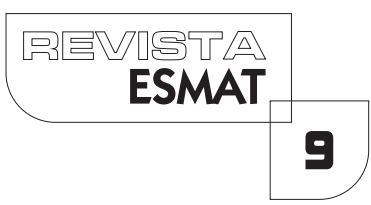

\title{
PROCESSO ADMINISTRATIVO E GARANTIAS CONSTITUCIONAIS
}

Angela Issa Haonat

Professora na Universidade Federal do Tocantins. Advogada em Palmas.

\section{RESUMO}

presente trabalho volta-se à análise do processo administrativo fundado na Constituição e nas garantias a ela inerentes. $\bigcirc$ objeto deste estudo é investigar se a marcha do processo administrativo observa os ditames constitucionais e se a ele se aplica a Teoria Geral do Direito. A preocupação central do trabalho foi destacar que existe um gap entre os processos jurisdicionais e os processos administrativos em matéria de se assegurarem as garantias constitucionais. A proposta do trabalho é demonstrar que a Teoria Geral do Direito é válida e deve ser observada em ambos. A Administração Pública pode e deve atuar com base nos princípios da segurança e da confiança, do devido processo legal, da ampla defesa, do contraditório e do juiz natural. A metodologia utilizada foi a análise da doutrina que serviu de aporte à presente investigação. Priorizaram-se os processos metodológicos do estudo dogmáticojurídico, analisando-se o ordenamento jurídico e tendo por centro a Constituição.

PALAVRAS-CHAVE: Constituição. Processo Administrativo.

\section{ABSTRACT}

This work returns to the analysis of the administrative process established in the Constitution and guarantees inherent to it. The object of this study is to investigate whether the march of the administrative process observes the constitutional principles and, if it applies to General Theory of Law. The central concern of this study was to highlight that there is a gap between the legal proceedings and administrative procedures relating to ensure constitutional guarantees. The purpose of this study is to demonstrate that the Law of the General Theory is worth and should be observed in both. Public administration can and should act on the basis of safety and trust, due process, legal defense, the adversarial and the natural judge. The methodology used was the analysis of the doctrine that served as a contribution to this research. Prioritized, methodological processes dogmatic-legal study analyzing the legal system, taking center by the Constitution.

KEYWORDS: Constitution. Administrative Process. 


\section{INTRODUÇÃO}

A presente pesquisa tem por objeto demonstrar que a Constituição, de 1988, rompe um paradigma ao ampliar as garantias processuais estendendo-as para além do conceito estrito de processo jurisdicional. Com a inserção do inciso LV do art. $5^{\circ}$ no plano da ordem jurídica, essas garantias vincularam igualmente os três Poderes instituídos. De outro modo, a Administração Pública, mesmo após 25 anos da Constituição é resiliente a essa mudança, e, com frequência, os processos administrativos padecem de vícios materiais e formais por inobservância aos princípios e garantias constitucionais.

A luta pela conquista dos direitos consagrados na Constituição é contínua e reflete o modelo e as necessidades da sociedade determinada, da época e lugar, razão pela qual se insere, na presente reflexão, que a função social do Direito está intimamente ligada à satisfação dos interesses que acompanham a evolução do homem e as transformações da sociedade. O que nos leva a abordar o tema da cultura jurídica, da linguagem, interpretação e aplicação do Direito, a fim de justificar as mudanças que marcaram a concepção de processo ao longo do tempo, propondo-se que essa cultura seja aplicada, também, aos processos administrativos contenciosos.

\section{I.I Breve retrospecto da cultura jurídica}

Como leciona Tércio Sampaio Ferraz Júnior (2001, p. 32), o Direito encontra-se vinculado a "uma série de símbolos, alguns mais eloquentes, outros menos, e que antecederam a própria palavra”.'

\footnotetext{
' Segundo o autor "De qualquer modo, o direito sempre teve um grande símbolo, bastante simples, que se materializava, desde há muito, em uma balança com dois pratos colocados no mesmo nível, com o fiel no meio - quando este existia - em posição perfeitamente vertical. Havia, ainda, outra materialização simbólica, que varia de povo para povo e de época para época. Assim, os gregos colocavam essa balança, com os dois pratos, mas sem o fiel no meio, na mão esquerda da Deusa Diké, filha de Zeus e Themis, em cuja mão direita estava uma espada e que, estando em pé e tendo os olhos bem abertos, dizia (declarava solenemente) existir o justo quando os pratos estavam em equilíbrio (íson, donde a palavra isonomia). Daí, para a língua vulgar dos gregos, o justo (o direito) significar o que era visto como igual (igualdade). Já o símbolo romano, entre as várias representações, correspondia, em geral, à deusa lustitia, a qual distribuía a justiça por meio da balança (com os dois pratos e o fiel bem no meio) que ela segurava com as duas mãos. Ela ficava de pé e tinha os olhos vendados e dizia (declarava) o direito (jus) quando o fiel estava completamente vertical: direito (rectum) $=$ perfeitamente reto, reto de cima a baixo (de + rectum).
} 
O Direito em sua qualidade de fenômeno cultural espelha valores há muito consagrados pelo homem. A sua compreensão pressupõe a nossa própria compreensão, pois, segundo Ferraz Júnior (200 I , p. 2 I), ao mesmo tempo em que liberta, também regula a liberdade concedida.

Como pondera Paulo Hamilton Siqueira Júnior (2009, p. 310), "a sociabilidade humana traz como característica a produção de valores. 0 convívio social se constrói por sentimentos e noções que traduzem o senso comum, que constituem a cultura de um povo".

Gustavo Zagrebelsky (2007, p. 65) associa o direito à liberdade, cujo tempo no dizer do autor é inexaurível. Segundo ele

[...] Os direitos em função da liberdade, ou seja, da vontade, são uma exigência permanente, pois permanente é a vontade que são chamados a proteger. A ideia dos direitos continuamente em ação está estreitamente conectada a do progresso individual e social, uma ideia que encerra em si a ausência de uma conclusão, de um final. Nas sociedades direcionadas ao progresso, os direitos são uma exigência estrutural. Sua difusão e seu potencial constituem fatores de aceleração a um caminho considerado fisiológico. $\bigcirc$ tempo desses direitos é inexaurível.

$[\ldots]$

Os direitos entendidos como pretensão de reparação de injustiça têm somente valor transitório à medida que perseguem a vigência da ordem justa e perdem significado uma vez alcançado o resultado. Nesse momento, os direitos em sentido subjetivo estão destinados a confundir-se com o direito objetivo. Em uma situação de justiça realizada, se algo é devido à alguém, não é porque tenha "direito", no sentido de uma pretensão de sua vontade, mas porque isto é imposto como dever da ordem do ser.

A conquista desses direitos á almejada tendo em vista que o homem luta para conquistá-los. E esta é uma luta contínua ao longo do tempo. ${ }^{2}$

\section{I.I.I Monopólio da cultura jurídica pelo Estado}

Atualmente o Estado detém o monopólio do Direito em sua acepção de garantia constitucional, mas esta foi uma conquista paulatina. Houve épocas,

\footnotetext{
${ }^{2}$ É o que se denota da Teoria da Dimensão/Geração dos Direitos, para demonstrar que ao longo do tempo o homem sempre lutou para conquistar novos direitos. À medida que são conquistados, não perdem a relevância, mas mudam de status, passando a ser mais que direitos, constituindo-se como deveres.
} 
especialmente as que antecederam a Revolução Francesa, em que se vivia sob o império da lei, sem qualquer limite para a vontade do soberano, que exercia de forma conjugada os poderes atinentes à atividade executiva, legislativa e judiciária. Adentrando-se na história, mesmo antes de sua existência na forma escrita, o Direito já se fazia presente ao estabelecer, por meio dos costumes, as regras de convivência em sociedade.

Carlos Ari Sundfield (2003, p. 29-34) elenca as formas de direito concebidas de acordo com cada época. Segundo o autor, na pré-história, embora precárias, as relações de poder já existiam e eram estabelecidas em razão da força, cujo emprego não era de ninguém em particular, em razão de o homem não se fixar num lugar em especial, como se deu na antiguidade, o período precedente. Na antiguidade, a cidade adquire status de unidade política, e a lei passa a existir como elemento imprescindível do convívio humano, sendo considerada imutável em razão de sua origem sagrada. A Idade Media é marcada pelo enfraquecimento de uma única autoridade central, e o poder passa a ser disputado entre outros, pelos reis, pela lgreja e pelos senhores feudais. Com a Idade Moderna, o poder retoma a forma centralizada em um só soberano e se caracteriza principalmente pela formação do Estado, nos moldes em que o poder soberano sujeita a todos os demais. Característica marcante dessa época revela-se na máxima "the king can do no wrong". Apenas na Idade Contemporânea ocorreram mudanças significativas no modelo de Estado, repercutindo na esfera do Direito. Com o advento dessa nova era, além das imposições e deveres, como a observância das leis e a submissão aos seus julgamentos, o Estado passa a editar normas de competência além das destinadas a controlar e limitar o seu próprio poder. $\bigcirc$ que representou à época uma grande conquista.

Pode-se assim dizer que é com o passar do tempo e em decorrência das constantes lutas do homem pela sua conquista que o Direito amolda-se às suas reais necessidades. Contudo, por mais que existam normas regulamentadoras dos comportamentos humanos, estas são frequentemente descumpridas, razão pela qual afirma Cássio Scarpinella Bueno (2008, p. 3) que se as normas materiais fossem suficientes por si mesmas, "certamente não haveria espaço ou necessidade de se pensar em normas de outra categoria, de outra classe, em normas de direito processual".

\section{I.2 Normas jurídicas materiais e processuais}

A classificação das normas jurídicas em materiais e processuais é matéria 
exaustivamente estudada na Teoria Geral do Direito, razão pela qual apenas se pontua o essencial para o contexto do presente trabalho, cujo tema central é o processo administrativo ambiental e a observância das normas a ele aplicáveis.

Por normas materiais e ou substanciais entende-se, de acordo com Antonio Carlos de Araújo Cintra et al (2005, p. 90), aquelas que cuidam da disciplina imediata da "cooperação entre pessoas e os conflitos de interesses ocorrentes na sociedade, escolhendo qual dos interesses conflitantes, e em que medida, deve prevalecer e qual deve ser sacrificado".

A própria definição já presume a impossibilidade de o Direito regrar todos os comportamentos, considerando a natureza humana, a possibilidade de o indivíduo voluntariamente, ou não, deixar de observar as normas postas. Razão pela qual se faz necessária outra natureza de normas que possibilitem a observância das normas materiais. Daí se falar em normas adjetivas, instrumentais e/ou processuais.

A norma processual, como explica Bueno (2008, p. 50-5I), "serve, atende e volta-se para a aplicação direta do direito material".

\section{I.2O processo na perspectiva constitucional}

A Constituição, de 1988, rompeu paradigmas, cujos dogmas eram bastante sedimentados. Não só em relação a direitos materiais, uma vez que o direito processual alcançou significativas conquistas que foram além das garantias no âmbito do processo jurisdicional, alcançando também o processo não jurisdicional. É o que se depreende do art. $5^{\circ}$, inciso LV ${ }^{4}$, da Constituição.

Como afirma Willis Santiago Guerra Filho (2005, p. 49), "[...] não há processo sem respeito ao efetivo contraditório", reconhecendo o autor que o referido princípio, "mais do que um princípio (objetivo) de organização do processo, judicial ou administrativo", afigura-se como "um princípio de organização do Estado, um direito". Em outras palavras, "trata-se de um verdadeiro direito fundamental processual".

4“LV - aos litigantes, em processo judicial ou administrativo, e aos acusados em geral são assegurados o contraditório e ampla defesa, com os meios e recursos a ela inerentes;". 
Ainda sem adentrar na questão do processo administrativo, a doutrina também é farta em discussões para eleger um conceito satisfatório que designe com clareza o significado de processo em sentido amplo (jurisdicional/não jurisdicional).

De modo que a análise do conceito de processo (jurisdicional) é ladeada por outros conceitos básicos, como jurisdição, ação, defesa e processo, que no que couber usar-se-á por analogia ao estudo do processo administrativo.

Essas concepções tradicionais atualmente não coadunam com a visão constitucional de processo, pois estes conceitos adquiriram status de direitos fundamentais ${ }^{7}$, além de se atrelarem aos princípios fundamentais e aos objetivos da República Federativa do Brasil (arts. $1^{\circ}$ e $3^{\circ}$ da Constituição).

O alerta de Eduardo de Avelar Lamy (20 I 0) é no sentido da necessidade de remodelar nossa cultura jurídica, mencionado que, além do conhecimento do direito positivo, é necessário um paradigma valorativo, que repense o processo, não da perspectiva de uma relação jurídica, mas como procedimento enriquecido pelo contraditório e em sua perspectiva fenomenológica.

Para Candido Rangel Dinamarco (2003, p. 33), "o processo que nos serve hoje há de ser o espelho e a salvaguarda dos valores individuais e coletivos que a ordem constitucional vigente entende de cultuar".

\section{I.3 Neoconstitucionalismo e processo}

Eduardo Ribeiro Moreira (2008, p. 65-66) leciona que "o desenvolvimento do neoconstitucionalismo apontará o paradigma jurídico deste início de século", posto que fundado em incrementos de racionalidade. Segundo o autor, o neoconstitucionalismo simboliza a luta do homem pela concretização e efetivação dos direitos. É o que se extrai da leitura dos pressupostos almejados por essa teoria, que resumidamente podem ser elencados como a "defesa dos direitos fundamentais, constituição rígida, mecanismos de separação de poderes e de freios e contra pesos [...]" entre outros. (MOREIRA, 2008, p. 66)

${ }^{6}$ Os clássicos Giuseppe Chiovenda, Francesco Carnellutti e Oscar Von Bulow contribuíram significativamente para a época, mas deixam a desejar quando se trata de processo na perspectiva constitucional.

${ }^{7}$ Constituição, art. 5, incisos XXXV, LV, LIV e LVI. 
Luís Roberto Barroso (2009, p. 5 I -52) afirma que "o Direito vive uma grave crise existencial. Não consegue entregar os dois produtos que fizeram sua reputação ao longo dos séculos. De fato, a injustiça passeia pelas ruas com passos firmes e a insegurança é característica da nossa era". Esse é o panorama que faz surgir as transformações advindas do neoconstitucionalismo, que Luís Roberto Barroso (2009, p. 52) resume em três marcos fundamentais: "o histórico, o teórico e o filosófico", cada qual, representando a fundamentalidade das mudanças que influíram de forma direta na constitucionalização do Direito.

Frise-se que a constitucionalização, no sentido empregado pelo autor, teve reflexos tanto no âmbito material dos diversos ramos do Direito, como no campo do direito processual, em sentido lato, para abrigar igualmente o processo jurisdicional e não jurisdicional. Especialmente em relação a este último, Luís Roberto Barroso (2009, p. 80-8I ) elenca os três aspectos que mais sofreram mudanças, listando-os como
a) a redefinição da ideia de supremacia do interesse público sobre o interesse privado $^{8}$
b) a vinculação do administrador à Constituição, e não apenas à lei ordinária ${ }^{9}$
c) a possibilidade de controle judicial do mérito do ato administrativo ${ }^{10}$

Eduardo Cambi (2006, p. 662) aponta a dúplice relação (direta e indireta) entre Constituição e processo. Segundo ele

\footnotetext{
${ }^{8}$ Para o autor, "Em relação a este tema, deve-se fazer, em primeiro lugar, a distinção necessária entre interesse público: (i) primário - isto é, o interesse da sociedade, sintetizado em valores como justiça, segurança e bem-estar social -, e, secundário, que é o interesse da pessoa jurídica de direito público (União, Estado e Municípios), identificando-se com o interesse da Fazenda Pública, isto é, do erário. Pois bem: o interesse público secundário jamais desfrutará de uma supremacia a priori e abstrata em face do interesse particular. Se ambos entrarem em rota de colisão, caberá ao intérprete proceder à ponderação desses interesses, à vista dos elementos normativos e fáticos relevantes para o caso concreto".

'Segundo Barroso, "Supera-se, aqui, a idéia restrita de vinculação positiva do administrador à lei, na leitura convencional do princípio da legalidade, pela qual sua atuação estava pautada por aquilo que o legislador determinasse ou autorizasse. $\bigcirc$ administrador pode e deve atuar tendo por fundamento direto a Constituição [...]. O princípio da legalidade transmuda-se, assim, em princípio da constitucionalidade [...]".

${ }^{10} \mathrm{~A}$ terceira modificação listada pelo autor é no sentido da ampliação do controle dos atos administrativos pelo judiciário, que era limitado aos aspectos da legalidade.
} 
A relação entre a Constituição pode ser feita de maneira direta, quando a lei fundamental estabelece quais são os direitos e as garantias processuais fundamentais, quando estrutura as instituições essenciais à realização da justiça ou, ainda, ao estabelecer os mecanismos formais de controle constitucional. Por outro lado, tal relação pode ser indireta, quando, tutelando diversamente determinado bem jurídico (por exemplo, os direitos de personalidade ou os direitos coletivos ou difusos) ou determinada categoria de sujeitos (crianças, adolescentes, idosos, consumidores etc), dá ensejo a que o legislador infraconstitucional preveja regras processuais específicas [...]

A contribuição do autor reforça a tese de que a Constituição dotada de força normativa insere-se de tal modo no centro do sistema, que as leis infraconstitucionais, que por hipótese a ela contrariem, possam ser retiradas do sistema por força do controle de constitucionalidade das leis.

Nesse contexto, a leitura do art. 5, LV, da Constituição, de 1988, não pode ser dissociada da ideia de força normativa da constituição que, balizada na Teoria do neoconstitucionalismo, aplica-se tanto à Administração Pública como ao processo de forma ampla - jurisdicional e administrativo.

Tal afirmação justifica-se nos ensinamentos de José Joaquim Gomes Canotilho( 1991, p. 192), para quem

aplicação directa não significa apenas que os direitos fundamentais se aplicam independentemente da intervenção legislativa (cfr. arts. 17. ${ }^{\circ}$ e 18.\%). Significa também que eles valem directamente contra lei, quando esta estabelece restrições em desconformidade com a constituição (cfr. CRP, art. I $.{ }^{\circ} / 3$ ).

É certo que o autor funda-se na Constituição Portuguesa", mas o art. $5^{\circ}, \S$ $1^{\circ}$, da Constituição, de 1988, possui regra semelhante "As normas definidoras dos direitos e garantias fundamentais têm aplicação imediata".

\footnotetext{
"Arts. 17 e 18 da Constituição da República Portuguesa "Artigo 17. Regime dos direitos, liberdades e garantias

O regime dos direitos, liberdades e garantias aplica-se aos enunciados no título II e aos direitos fundamentais de natureza análoga.

Artigo 18. ${ }^{\circ}$ Força jurídica

I. Os preceitos constitucionais respeitantes aos direitos, liberdades e garantias são directamente aplicáveis e vinculam as entidades públicas e privadas.

2. A lei só pode restringir os direitos, liberdades e garantias nos casos expressamente previstos na Constituição, devendo as restrições limitar-se ao necessário para salvaguardar outros direitos ou interesses constitucionalmente protegidos.

3. As leis restritivas de direitos, liberdades e garantias têm de revestir carácter geral e abstracto e não podem ter efeito retroactivo nem diminuir a extensão e o alcance do conteúdo essencial dos preceitos constitucionais.
} 
Diante desse preceito, não há interpretação possível de afastar a incidência dessa regra no âmbito do processo administrativo.

\section{A LINGUAGEM E O SIGNIFICADO COMO PRESSUPOSTOS DA APLICAÇÃO DO DIREITO}

Em razão de múltiplas acepções do vocábulo processo, bem como da divergência existente na doutrina acerca das terminologias processo e procedimento administrativo, ressalta-se a importância deste tópico que trabalha a linguagem e o significado como pressupostos da aplicação do Direito, tendo em vista os pontos comuns e divergentes entre o processo/procedimento jurisdicional, e não jurisdicional.

Hans-Georg Gadamer (2002, p. 73) lembra a clássica definição de homem em Aristóteles, como "o ser vivo que possui logos" que, entre os ocidentais, pode ser compreendida como o cânone do animal racional. Menciona ainda que a palavra grega logos possui também acepção de linguagem. Nesse contexto, o autor aponta para o fato de a linguagem não representar uma espécie de instrumento ou ferramenta, mas sim "um processo enigmático e profundamente oculto".

Observa Gadamer (2002, p. 178) que "em nossos pensamentos e conhecimentos sempre já fomos precedidos pela interpretação do mundo feita na linguagem, e essa progressiva integração no mundo chama-se crescer". Tudo isso, segundo ele, nos dá conta de que a linguagem nos extrapola, representando mesmo "o verdadeiro vestígio de nossa finitude", visto que o parâmetro de sua medida não está em nossa consciência individual, tampouco na reunião das consciências individuais. E nesse sentido conclui

\footnotetext{
A linguagem é, pois, o centro do ser humano, quando considerado no âmbito que só ela consegue preencher: o âmbito da convivência humana, o âmbito do entendimento, do consenso crescente, tão indispensável à vida humana como o ar que respiramos. Realmente o homem é o ser que possui linguagem, segundo a afirmação de Aristóteles. Tudo que é humano deve ser dito entre nós. (GADAMER, 2008, p. 182)
}

Tomando por parâmetro o lecionado pelo autor, a linguagem e seu processo são fundamentais à convivência humana em sociedade, e, como tal, têm profunda ligação com o Direito.

Alaôr Caffé Alves (2002, p. 26) leciona que é por meio da linguagem e de seus elementos que podemos externar as coisas passíveis de existência. Diante 
dessa constatação, o autor afirma que "[...] o pensamento, para existir, não prescinde de uma formulação lingüística. [...] embora ele não se confunda com a linguagem, não se pode tê-lo expressamente sem esta”. Para o autor, pensamento e linguagem, embora não sejam a mesma coisa, possuem uma inter-relação que não pode ser subestimada, razão pela qual conclui que o homem "pensa porque fala, bem como fala porque pensa". A importância do lecionado pelo autor está no encadeamento da linguagem como fenômeno intersubjetivo e sua conexão com as relações sociais de uma dada sociedade em determinado tempo.

Como afirma Lourival Vilanova (2005, p. 40), "mediante a linguagem fixamse as concepções conceptuais e se comunica o conhecimento".

A análise da linguagem liga-se de forma umbilical ao estudo do significado (FERREIRA, 1999, p. I.853) que, em sentido amplo, pode ser compreendido como "aquilo que uma língua expressa acerca do mundo em que vivemos ou acerca de um mundo possível" e, ainda, como significado gramatical, "aquele que se estabelece dentro de um sistema lingüístico determinado e que dele depende" e, por fim, o significado lexical, compreendido como "aquele que se estabelece em relação ao mundo biossocial".

Ao transpor as questões atinentes à linguagem e ao significado do campo geral para a função da Ciência do Direito, de acordo com Humberto Ávila (2009, p. 3l), esta "não pode ser considerada como mera descrição do significado, quer na perspectiva da comunicação de uma informação ou conhecimento a respeito de um texto, quer naquela intenção de seu autor".

A constatação do autor está ligada ao estudo da hermenêutica e da interpretação do Direito, as quais, por seu turno, estão interligadas à questão dos princípios jurídicos, temas a serem estudados em capítulo próprio.

Nesse sentido, também contribui Plauto Faraco de Azevedo ( 1996, p. 73), atribuindo importância extrema ao domínio da linguagem, visto que a ausência desta influenciará de forma direta na aplicação do Direito, tornando assim as leis confusas por semear "a perplexidade entre as pessoas, dificultando-lhes o conhecimento de seus direitos e deveres."

Tais apontamentos servem de introdução à discussão que paira na doutrina acerca da nomenclatura processo/procedimento administrativo, como lecionam Sérgio Ferraz e Adilson Abreu Dallari (2000, p. 18- 19),

[...] a palavra assume, na ciência jurídica, importância idêntica (ou quase) à do pensamento. Como ciência essencialmente relacional, ela fatalmente tem que ser transmitida, e transmitida à coletividade de iniciados e principiantes. [...] É por força dessa característica que se registra fenômeno marcante no mundo do 
Direito: mesmo expressões de uso exclusiva ou predominantemente jurídico não tem sentido unívoco, no tempo e no espaço. [...] Longe, entretanto, de se ter, aqui, um obstáculo, a ciência jurídica assim garante sua perene revitalização. É exatamente porque, nos diferentes tempos e sítios, a linguagem comum, adaptando-se às vertentes ideológicas determinantes, exprime fenômenos diversos que a lei, por utilizar tais expressões, também pode sobreviver às crises, na medida, particularmente, em que a doutrina e a jurisprudência saibam captar os novos informadores a serem reverenciados.

Sob este prisma, passa-se à análise do processo administrativo em espécie e como esse instituto está disciplinado na Constituição, de 1988, enfrentando-se ainda a polêmica acerca da nomenclatura processo/procedimento administrativo.

\section{PROCESSO ADMINISTRATIVO}

Ferreira ( I 999, p. I.64 I) atribui significados distintos ao vocábulo processo, levando em conta o seu sentido jurídico

processo. [Do lat. processu]. [...] 5. Jur. Atividade por meio da qual se exerce concretamente, em relação a determinado caso, a função jurisdicional, que é instrumento de composição das lides. 6. Jur. Pleito judicial; litígio. 7. Jur. Conjunto de peças que documentam o exercício da atividade jurisdicional em um caso concreto; autos: a leitura do processo. (FERREIRA, 1999, p. I64I).

Das múltiplas acepções atribuídas pelo autor, verifica-se que ora o processo significa atividade da função jurisdicional, ora significa a própria lide e ora significa o conjunto de procedimentos que compõem a lide. $\bigcirc$ significado de procedimento, segundo Ferreira ( 1999, p. I.64 I), significa em sentido jurídico "Formas que a lei estabelece para se tratarem as causas em juízo. 6. Jur. Formas à que está subordinado o cumprimento dos atos e trâmites do processo".

Celso Antonio Bandeira de Mello (2010, p. 486-488) ressalta que "não é o caso de armar um "cavalo de batalha" em torno de rótulos". Para ele, não obstante a relevância do tema, posto que atua "como instrumento de garantia dos administrados ante as prerrogativas públicas", a divergência quanto a terminologia é-lhe indiferente, pois ambas sustentam-se respectivamente na Lei Federal n 9.784, de 1999 (processo), e na tradição do Direito Administrativo (procedimento).

Imperioso perceber que o que está por traz da discussão doutrinária, mais que imprecisão terminológica, é a discussão acerca do conteúdo dos conceitos, 
ou seja, é questão muito mais relativa à Teoria Geral do Direito. ${ }^{12}$

Há também de se emprestar a devida vênia ao texto constitucional que de forma clara faz referência ao termo processo administrativo. No escólio de Celso Antonio Bandeira de Mello (2010, p. 488) também a Lei n 9.784, de 1999, de forma expressa (art. $\left.1^{\circ}\right)^{13}$, utiliza a terminologia processo.

Cândido Rangel Dinamarco (2003, p. 75-76 e 83-84) leciona que "há processos estatais e não-estatais". Os primeiros podem ser compreendidos como processos jurisdicionais (jurisdição contenciosa e jurisdição voluntária), o processo legislativo e o processo da Administração Pública. Segundo ele, embora a tradição seja a utilização da nomenclatura processo para designar o processo jurisdicional stricto sensu

[...] é do direito administrativo que veio a mais clara das idéias acerca do conceito de processo, hoje alvo de crescente aceitação na doutrina dos processualistas: procedimento com participação dos sujeitos interessados (ou seja, daqueles que receberão a eficácia direta do ato final esperado), eis o conceito de processo na ciência moderna. [...]

À medida que a atenção do administrativista passou a voltar-se à existência desse processo e à sua problemática, descobrindo e definindo princípios, a escalada para o patamar mais elevado de abstração foi pari passu inaugurada. (DINAMARCO, 2003, p. 83-84).

A análise das questões relativas ao conceito e conteúdo das terminologias processo e procedimento - está ligada ainda a outra questão de fundo, que é a própria dificuldade de constitucionalização do Direito Administrativo. De acordo com Marcelo Lamy (s/d, p. 27),

\footnotetext{
${ }^{12}$ Tal qual a definição do direito, definir a Teoria Geral do Direito não é tarefa simples. Ao longo do tempo, muitos conceitos foram construídos e reconstruídos a partir da análise dos sistemas jurídicos. Dimitri Dimoulis menciona algumas definições clássicas da disciplina, citando autores como Van Hoecke e Ost, Manuel e Atienza entre outros. A título de ilustração, descrevemos algumas dessas definições. Para Van Hoecke e Ost citados por Dimitri Dimoulis a Teoria Geral do Direito é "ramo da ciência do Direito cuja finalidade é a análise crítica [...] a partir de uma perspectiva interdisciplinar dos diferentes aspectos do direito e dos fenômenos jurídicos". Para Atienza citado por Dimoulis (2006, p. 17), ${ }^{12}$ a disciplina cuida da "análise dos conceitos jurídicos fundamentais que são comuns aos sistemas jurídicos ou ramos do direito".

${ }^{13}$ Art. Io Esta Lei estabelece normas básicas sobre o processo administrativo no âmbito da Administração Federal direta e indireta, visando, em especial, à proteção dos direitos dos administrados e ao melhor cumprimento dos fins da Administração. (grifo nosso).
} 
Assim como no Direito Constitucional encontramos o desenho jurídico estruturante da Administração Pública, no Direito Administrativo encontramos os instrumentais para a realização e a efetivação do que a Constituição previu. Diante de tal interdependência, não pode haver conflito entre o modelo constitucional e a legislação administrativa. No mesmo sentido, e em prol da unidade do ordenamento jurídico, não pode existir qualquer tensão, divórcio ou discrepância entre as dimensões constitucionais e administrativas. [...] Existe, sem dúvida, um compromisso constitucional fundante relativo ao modelo jurídico que deve presidir o processo administrativo.

A presente pesquisa aponta como na prática a Administração Pública, ${ }^{14}$ dissocia-se das garantias constitucionais orientadoras do processo, pois em que pese a possibilidade da oportunidade de participação (contraditório) por meio de apresentação de defesa administrativa, esta apenas é analisada em seu aspecto formal, em total desprezo às questões de fundo, que possibilitariam o exercício real do princípio do contraditório.

Em resumo, o processo na perspectiva constitucional, seja ele jurisdicional e ou não jurisdicional, respeitando-se logicamente as distinções quanto à natureza de cada qual, vinculam-se sem qualquer desmerecimento a uma Teoria Geral do Direito, única.

\section{I Conceito de Processo Administrativo}

Para Marcello Caetano (2004, p. I .287), a noção de processo lato sensu é inerente à atividade da Administração Pública. Nesse sentido, o termo processo é compreendido como "sucessão ordenada de formalidades preestabelecidas tendente à formação ou à execução de uma vontade funcional". Dando-nos conta de que em sentido amplo, processo compreende a totalidade dos atos administrativos. Resta-nos destacar que essa concepção que é a lógica da atuação da Administração Pública abriga ainda uma classificação de processo

\footnotetext{
${ }^{14}$ Administração Pública, de acordo com (DI PIETRO, 20003, p. 54), pode ser compreendida em dois sentidos: "a) em sentido subjetivo, formal ou orgânico, ela designa os entes que exercem a atividade administrativa; compreende pessoas jurídicas, órgãos e agentes públicos incumbidos de exercer uma das funções em que se triparte a atividade estatal: a função administrativa. b) em sentido objetivo, material ou funcional, ela designa a natureza da atividade exercida pelos referidos entes; nesse sentido, a Administração Pública é a própria função administrativa que incumbe, predominantemente, ao Poder Executivo."
} 
administrativo em sentido estrito, mas que no bojo da presente pesquisa cuidarse-á apenas do processo administrativo sancionador externo. ${ }^{15}$

$\bigcirc$ processo administrativo sancionador, como leciona Marcello Caetano (2004, p. I.304), destina-se "à aplicação de sanção cominada por lei a um particular infractor". Segundo o mesmo autor, estes processos

[...] são de carácter misto visto neles a iniciativa da Administração se exercer para cumprir a lei ou assegurar a boa ordem dos serviços, mas pondo em causa um particular a quem se tem que assegurar o direito de defesa.

Quer a lei o diga expressamente quer não, em tais processos há que respeitar o princípio de que ninguém pode ser condenado sem previamente ter sido ouvido, compreendendo-se neste direito natural de defesa a instrução contraditória [...] (MARCELLO CAETANO, 2004, p. 1304).

Por seu turno, Egon Bockmann Moreira (b) (2010, p. 63-64) define o processo administrativo como "relação jurídica dinâmica, coordenada por normas que estabelecem vínculo de segundo grau entre os sujeitos que dele participam". O autor chama ainda a atenção para o fato de que, embora se constitua uma realidade autônoma, o processo administrativo está conectado ao "sistema jurídico de direito positivo, tal qual como consignado na Constituição da República”.

\subsection{O Processo Administrativo como direito fundamental na Constituição, de 1988}

De acordo com Canotilho (|99|, p. 597), "o processo de fundamentalização, constitucionalização dos direitos fundamentais colocou o indivíduo, a pessoa, o homem, como ponto central da titularidade de direitos". O art. $5^{\circ}$ da Constituição, de 1988, tem a seguinte redação

"Art. $5^{\circ}$ Todos são iguais perante a lei, sem distinção de qualquer natureza,

\footnotetext{
${ }^{15}$ Vide classificação de MEDAUAR ( 1993, p. 1 32), que em uma concepção macro classifica-os em (i) processos administrativos em que há conflito de interesses e (ii) processos administrativos sancionadores. Entre os primeiros, a autora destaca como subespécies os processos administrativos de gestão; os processos administrativos de outorga; os processos administrativos de verificação; e, os processos administrativos de revisão; e, entre os segundos estão os processos administrativos sancionadores internos e externos (estes últimos, que decorrem do poder de polícia é que serão analisados).
} 
garantindo-se aos brasileiros e aos estrangeiros residentes no País a inviolabilidade do direito à vida, à liberdade, à igualdade, à segurança e à propriedade, nos termos seguintes [...]" (grifo nosso)

José Afonso da Silva (2008, p. 178), depois de mencionar as várias nomenclaturas usadas para designar os direitos fundamentais do homem, conceitua-os como

[...] a expressão mais adequada a este estudo, porque, além de referir-se a princípios que resumem a concepção do mundo e informam a ideologia política de cada ordenamento jurídico, é reservada para designar, no nível do direito positivo, aquelas prerrogativas e instituições que ele concretiza em garantias de uma convivência digna, livre e igual de todas as pessoas. No qualificativo fundamentais acha-se a indicação de que se trata de situações jurídicas sem as quais a pessoa humana não se realiza, não convive e, às vezes, nem mesmo sobrevive; fundamentais do homem no sentido de que a todos, por igual, devem ser, não apenas formalmente reconhecidos, mas concreta materialmente efetivados. (SILVA, 2008, p. 178).

Ao citar o art. $5^{\circ}$, caput, da Constituição, de 1988, deu-se realce especial à expressão "aos brasileiros e aos estrangeiros residentes no País", com o propósito de demonstrar que os direitos e garantias expressos no artigo mencionado estendem-se às pessoas jurídicas naquilo que for com elas compatível.

Outra contribuição importante para albergar a tese da fundamentalidade do processo administrativo na Constituição, de 1988, está no lecionado por Gustavo de Medeiros Melo (2006, p. 693), ao lembrar que o Congresso Nacional, sensível à questão, elaborou a Lei no 9.784, de 1999. Destaca o autor que

Logo se vê em dispositivo dedicado aos princípios e critérios norteadores da atividade administrativa que são garantidos os direitos à comunicação, à apresentação de alegações finais, à produção de provas e à interposição de recursos, nos processos que possam resultar sanções e nas situações de litígio (Lei 9.784/1999, art. $2^{\circ}, X$ ).

Na seqüência, em disposição referente aos direitos do administrado, lê-se que a ele é dado formular alegações e apresentar documentos antes da citação, os quais serão objeto de consideração pelo órgão competente (Lei 9.784/I 999, $\left.\operatorname{art.} 3^{\circ}, 111\right)$.

Com as observações do autor, tem-se que a garantia do processo justo está contida não só na Constituição, de 1988, mas também a Lei n 9.784, de 1999 , 
assegura de forma expressa o momento e a forma da concretização dessas garantias.

Ademais, segundo ainda Melo (2006, p. 693), "as prescrições em foco representam elogiável consciência do legislador para com aquele que, outrora posicionado como mero objeto da acusação, passou a ser tratado como sujeito da relação processual", subtendendo-se daí as possibilidades de "alegar, contraditar, provar e influir no resultado do julgamento".

A exemplo de garantia efetiva de um processo administrativo justo, Marcelo Lamy (s/d, 32-33) elenca, entre outros, o exemplo do art. 268, 4, da Constituição Portuguesa, ${ }^{16}$ lecionando que

[...] o particular deixou de ser entendido como administrado (um mero objeto de poder), para ser visto como um sujeito de direito que estabelece relações jurídicas com a Administração. Se o particular não é somente administrado, mas sujeito; o processo administrativo não é mero mecanismo de verificar a legalidade, mas um percurso que descobre os interesses de todos os envolvidos, procurando compatibilizá-los, harmonizá-los ou, se precisar estabelecer alguma preferência, garantir os direitos fundamentais.

Assim, de acordo com Egon Bockmann Moreira (2003, p. I 28), "o processo administrativo deve ser alçado a uma dignidade superior". O que demanda que as decisões proferidas no âmbito do processo administrativo aproximem-se em grau de independência dos processos jurisdicionais. É também o que se depreende dos ensinamentos de Elio Fazzalari (2006, p. 7I5), que aponta inexistirem nos processos administrativos "a independência e estranheza do autor da decisão em relação à realidade substancial (ato administrativo)".

Não se pode preterir que a partir da Constituição, de 1988, o administrado adquire o status de sujeito de direitos, e o processo administrativo alcança garantias até então reservadas aos processos jurisdicionais. $\bigcirc$ que pode ser observado na doutrina e na jurisprudência, pela mitigação do princípio da reserva legal, que passa a conceder ao julgador margem de significativa intervenção nas razões de conveniência e oportunidade, analisando os atos

\footnotetext{
${ }^{16}$ Art. 268, 4. É garantido aos administrados tutela jurisdicional efectiva dos seus direitos ou interesses legalmente protegidos, incluindo, nomeadamente, o reconhecimento desses direitos ou interesses, a impugnação de quaisquer actos administrativos que os lesem, independentemente da sua forma, a determinação da prática de actos administrativos legalmente devidos e a adopção de medidas cautelares adequadas. (grifo nosso)
} 
contestados, sob os critérios da finalidade, razoabilidade, eficiência e moralidade. Tese que se comprova pelo fato de não ser exigível o esgotamento da esfera administrativa, a não ser os casos assim previstos na Constituição (Justiça Desportiva), o que de outro lado efetiva a busca da tutela jurisdicional (art. Xxxv da Constituição).

\section{CONSIDERAÇÕES FINAIS}

A inserção da Constituição, de 1988, como o centro do ordenamento jurídico, representou o rompimento de um paradigma que teve reflexo em todos os ramos do Direito. Esse rompimento, no entanto, não ocorreu igualmente para todos os ramos. No âmbito da Administração Pública é perceptível que ainda há muito para ser feito. Pode-se atribuir ainda à Constituição um papel de relevância ao inserir entre suas garantias, não apenas aquelas afeitas aos direitos materiais, mas também as que se referem aos direitos processuais. Podendo-se elencar o Direito ao devido processo legal, a duração razoável do processo, a ampla defesa e o contraditório, estendendo-se todas essas não só aos processos jurisdicionais, como também aos processos administrativos.

Soube a Constituição conciliar interesses e direitos aparentemente distintos, impondo, como centro do sistema que é, os limites considerados necessários. Mas a conquista mais significativa que se pode atribuir à Constituição foi estabelecer os princípios fundamentais do Estado Democrático de Direito e, entre eles, a dignidade da pessoa humana. Isso significa que a dignidade da pessoa humana passa a ser um princípio vetor. As ações do Estado Democrático de Direito devem pautar-se na compatibilização desses princípios com os objetivos fixados pela República Federativa do Brasil.

Pretendeu-se ressaltar que ainda existe um gap em matéria de garantias entre os processos jurisdicionais, sejam eles cíveis ou penais, os quais se pautam na Constituição, e os processos administrativos. Nos processos jurisdicionais, observa-se o devido processo legal, o contraditório, a ampla defesa, o princípio do juiz natural e as questões pertinentes às provas. No âmbito penal, a lei prevê expressamente a possibilidade da exclusão da ilicitude, especialmente em razão da pessoa e na dosimetria da pena o juiz leva em conta as condições em que o autor cometeu o ilícito.

A Administração Pública cerca-se de resistência em reconhecer a isonomia entre os processos jurisdicionais e não jurisdicionais, ou seja, de perceber a Constituição como centro do sistema. Ao fazer prevalecer o princípio da 


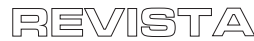

ESMAT

supremacia do interesse público sem qualquer forma de mitigação, esquece-se de que a Teoria Geral do Direito é una, e, portanto, o processo administrativo deve observar os comandos constitucionais que garantem ao administrado o status de sujeito de direito.

\section{REFERÊNCIAS}

ALVES, Alaôr Caffé. Lógica: pensamento formal e argumentação: elementos para o discurso jurídico. São Paulo: Quartier Latin, 2002.

ÁVILA, Humberto. Teoria dos Princípios: da definição à aplicação dos princípios jurídicos. 9a ed. rev. e amp. São Paulo: Malheiros, 2009.

AZEVEDO, Plauto Faraco de. Aplicação do Direito e contexto social. Revista dos Tribunais: 1996.

BARROSO, Luís Roberto. Neoconstitucionalismo e constitucionalização do direito (o triunfo tardio do direito constitucional no Brasil). In: Neoconstitucionalismo. Coordenadores: Regina Quaresma, Maria Lúcia de Paula Oliveira e Farlei Riccio de Oliveira; Alejandro Pérez Hualde ... [... . et al. Rio de Janeiro: Forense, 2009.

BRASIL. Constituição da República Federativa do Brasil. Disponível no site www.planalto.gov.br. Acesso em 26 de junho de 2015.

BUENO, Cássio Scarpinella Bueno. Curso sistematizado de direito processual civil: teoria geral do processo civil. $2^{\mathrm{a}}$ ed. rev., atual e amp. São Paulo: Saraiva, 2008.

CAETANO, Marcello. Manual de direito administrativo. $10^{\mathrm{a}}$ ed. 7, reimpressão revista e actualizada por Diogo Freitas do Amaral. Tomo II. Coimbra: Almedina, 2004.

CAMBI, Eduardo. Neoconstitucionalismo e neoprocessualismo. In: Processo e Constituição: Estudos em homenagem ao Professor José Carlos Barbosa Moreira. Coordenação: Luiz Fux, Nelson Nery Jr e Teresa Arruda Alvim Wambier. São Paulo: Revista dos Tribunais, 2006. 
CANOTILHO, José Joaquim Gomes. Direito Constitucional. $5^{a}$ ed. Coimbra: Almedina, 1991.

CINTRA, Antonio Carlos de; GRINOVER, Ada Pelegrini; e DINAMARCO, Candido Rangel. Teoria Geral do Processo. $21^{\text {a }}$ ed. São Paulo: Malheiros, 2005.

DI PIETRO, Maria Sylvia Zanella. Direito Administrativo. $5^{a}$ ed. São Paulo: Atlas, 2003.

DIMOULIS, Dimitri. Positivismo Jurídico: introdução a uma teoria do direito e defesa do pragmatismo jurídico-político. São Paulo: Método, 2006, p. 17.

DINAMARCO, Cândido Rangel. A instrumentalidade do processo. II ed. revista e atualizada. São Paulo: Malheiros, 2003.

FAZZALARI, Elio. Instituições de Direito Processual. Tradução de Elaine Nassif. Campinas/SP: Bookseller, 2006.

FERRAZ Júnior, Tércio Sampaio. Introdução ao Estudo do Direito: técnica, decisão, dominação. 3 ed. São Paulo: Atlas, 2001 .

FERRAZ, Sérgio; DALLARI, Adilson de Abreu. Processo Administrativo. ${ }^{\text {a }}$ ed. $3^{a}$ tiragem. São Paulo: Malheiros, 2000.

FERREIRA, Aurélio Buarque de Holanda. Novo Aurélio Século XXI: o dicionário da língua portuguesa. $3^{\mathrm{a}}$ ed. rev. e amp. Rio de Janeiro: Nova Fronteira, 1999, p. I.853.

GADAMER, Hans-Georg. Verdade e Método Il: complemento e índice. $2^{a}$ ed. Tradução de: Enio Paulo Gianchini. Revisão da Tradução: Márcia Sá Cavalcante Schuback. Petrópolis-RJ: Vozes. Bragança Paulista-SP: Editora Universitária São Francisco, 2002.

GUERRA FILHO, Willis Santiago. Processo constitucional e direitos fundamentais. $4^{\mathrm{a}}$ ed. rev. e ampl. São Paulo: RCS, 2005.

LAMY, Eduardo de Avelar. Notas de aula do IV módulo do Curso de Pós Graduação em Direito Civil e Processual Civil, na Faculdade Católica do 


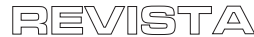

Tocantins, em 3/I2/20 I 0.

LAMY, Marcelo. A difícil constitucionalização do processo administrativo. Curso de Direito Constitucional Administrativo. Bloco II. p. 27 s/d.

MARTINS, Ricardo Marcondes. O conceito científico de processo administrativo. In: Revista de Direito Administrativo. Rio de Janeiro: Renovar. Título autorizado pela Fundação Getúlio Vargas, v. 235. jan/mar, 2004, p. 321 381 .

MEDAUAR, Odete. A processualidade no direito administrativo. São Paulo: Revista dos Tribunais, 1993, p. 132.

MELLO, Celso Antonio Bandeira de. Curso de Direito Administrativo. 27 ed. Revista e atualizada até a Emenda Constitucional 64, de 4/2/20 I0. São Paulo: Malheiros, 2010.

MELO, Gustavo de Medeiros. $O$ acesso adequado à justiça na perspectiva do justo processo. In: Processo e Constituição: estudos em homenagem ao professor José Carlos Barbosa Moreira. Coordenação: Luiz Fux, Nelson Nery Júnior e Teresa Arruda Alvim Wambier. São Paulo: Revista dos Tribunais, 2006.

MOREIRA, Eduardo Ribeiro. Neoconstitucionalismo e teoria da interpretação. In: Revista de Direito Constitucional e Internacional. Diretora Geral e Coordenadora: Maria Garcia. Ano I 6. n 63. abr-jun, 2008.

MOREIRA, Egon Bockmann. Processo administrativo: principios constitucionais e a Lei 9.784/1999. $4^{a}$ ed. atualizada, revista e aumentada. São Paulo: Malheiros, 2010.

(b). O processo administrativo no rol dos direitos e garantias individuais. In: Revista Trimestral de Direito Público. São Paulo: Malheiros. 43/2003.

SILVA, José Afonso da. Curso de direito constitucional positivo. $32^{\mathrm{a}}$ ed. São Paulo: Malheiros, 2008.

SIQUEIRAJR., Paulo Hamilton. Teoria do Direito. São Paulo: Saraiva, 2009. 
SUNDFIELD, Carlos Ari. Fundamentos de Direito Público. $4^{\mathrm{a}}$ ed. 4 tiragem. São Paulo: Malheiros, 2003.

VILANOVA, Lourival. As estruturas lógicas e o sistema de direito positivo. São Paulo: Noeses, 2005.

ZAGREBELSKY, Gustavo. Direitos de liberdade e direitos de justiça. Tradução: Guilherme Leite Gonçalves. Revisão de Carolina Cadavid. In: Revista de Direito Administrativo. Maio/Agosto de 2007. São Paulo: Atlas, 2007. 